\title{
Oxidative Stress in Extrahepatic Tissues of Rats Co-Exposed to Aflatoxin B1 and Low Protein Diet
}

\author{
Oluwakemi A. Rotimi', Solomon O. Rotimi ${ }^{1}$, Flora Oluwafemi' ${ }^{2}$, Oladipo Ademuyiwa ${ }^{3}$ \\ and Elizabeth A. Balogun ${ }^{4}$ \\ ${ }^{1}$ Department of Biochemistry, Covenant University, Ota, Nigeria \\ ${ }^{2}$ Department of Microbiology, Federal University of Agriculture, Abeokuta, Nigeria \\ ${ }^{3}$ Department of Biochemistry, Federal University of Agriculture, Abeokuta, Nigeria \\ ${ }^{4}$ Department of Biochemistry, University of Ilorin, Ilorin, Nigeria
}

\begin{abstract}
Early life exposure to aflatoxin B1 (AFB1) and low protein diet through complementary foods during weaning is common in parts of Africa and Asia. This study evaluated the effect of co-exposure to AFB1 and low protein diet on the extrahepatic tissues of rats. Twenty-four three-week old weanling male albino rats were used for this study and were randomly assigned into four groups: group 1 served as control and was fed normal protein diet $(20 \%$ protein), group 2 was fed low protein diet (5\% protein), group 3 was fed normal protein diet +40 ppb AFB1 while group 4 received low protein diet $+40 \mathrm{ppb}$ AFB1, all for eight weeks. Afterward, biomarkers of anemia (packed cell volume (PCV), hemoglobin) and kidney function (urea, uric acid, and creatinine) were determined in the blood while biomarkers of oxidative stress were determined in the tissues spectrophotometrically. Co-exposure to AFB1 and low protein diet significantly $(p<0.05)$ decreased body weight gain and PCV, increased biomarkers of kidney functions and induced oxidative stress in the tissues studied. There was significant $(p<0.05)$ reduction in glutathione concentration while TBARS was significantly increased in the tissues. Co-exposure to AFB1 and low protein diet had additive effects on decreasing the weight gain and potentiation effect of kidney dysfunction in the rats. The co-exposure also decreased antioxidant enzymes and increased oxidant status in the tissues. Our results demonstrate that this co-exposure has deleterious health effects on extrahepatic tissues and should be a public health concern especially in developing countries where AFB1 contamination is common.
\end{abstract}

Key words: Aflatoxin B1, Low protein, Oxidative stress, Extrahepatic tissues

\section{INTRODUCTION}

Aflatoxins are secondary metabolites of fungi belonging to the Aspergillus species including $A$. flavus and $A$. parasiticus. They contaminate staple foods- like grains and nuts- in the tropical and subtropical areas of Africa and Asia during pre - and post-harvest conditions $(1,2)$.

Correspondence to: Oluwakemi A. Rotimi, Department of Biochemistry and Molecular Biology Research Laboratory, Covenant University, Ota, Ogun State, 112101, Nigeria

E-mail: kemi.rotimi@covenantuniversity.edu.ng

This is an Open-Access article distributed under the terms of the Creative Commons Attribution Non-Commercial License (http:// creativecommons.org/licenses/by-nc/3.0) which permits unrestricted non-commercial use, distribution, and reproduction in any medium, provided the original work is properly cited.
They are also found in eggs, milk, and meat of animals exposed to aflatoxin-contaminated feed, including herbal medicine (3). The major types of naturally occurring aflatoxins are aflatoxin B1 (AFB1), aflatoxin B2, aflatoxin G1, and aflatoxin G2 while aflatoxin $\mathrm{M}$ is a metabolite of AFB1 found in the milk of humans and animals exposed to aflatoxins (4). Of the major aflatoxins, AFB1 is the most toxic and the most common. Accounting for $70 \%$ of total aflatoxin in food, it has been designated as a class $1 \mathrm{~A}$ carcinogen by the International Agency for Research of Cancer (IARC). After ingestion, AFB1 is rapidly absorbed and metabolized in the liver by a variety of $\mathrm{CYP}_{450}$ enzymes to a highly reactive AFB1 8 , 9, epoxide (5). This epoxide covalently binds to cellular macromolecules such as proteins and nucleic acid leading to protein degradation and genetic damage respectively $(6,7)$. Apart from 
these adverse effects, AFB1 have also been found to be hepatotoxic, immunosuppressive (8) and cause growth faltering in children due to early life exposure (9).

Early life exposures to aflatoxins occur in utero via placental transfer (10), through mothers' breast milk (9) and through weaning foods (11). During weaning, exposure to aflatoxins is unusually high due to the introduction of cereal-based complementary foods, which are highly susceptible to aflatoxin contamination (4). Studies by Gong et al. $(11,12)$ found that children that were wholly weaned had 2 times higher aflatoxin levels than those still partially breastfed. Infants and young children in different parts of Africa have been found to be exposed to aflatoxins due to the high rate of consumption of maize-based weaning foods (13-15). To further exacerbate the potential harm to children, these weaning foods are not only contaminated with aflatoxins, but they are also usually low in protein.

Low protein diet during weaning could lead to proteinenergy malnutrition, an imbalance between the supply and requirements of protein and energy, which is a serious health problem in parts of Africa and Asia where aflatoxin contamination exists $(4,16)$. This leads to a situation of co-existence of aflatoxin poisoning and protein malnutrition. Protein malnutrition affects body organs (17) and induces oxidative stress, an imbalance between the body's free radicals and its capability to combat these radicals because proteins are required for the synthesis of antioxidant enzymes that combat free radicals (18).

Although the liver is the target organ of AFB1, it affects other body organs. It increases oxidative stress in rat kidney thereby leading to changes in renal function and ultimately causing kidney damage. It has also been shown to increase oxidative stress and apoptosis in the spleen of broilers (19-24). The hepatotoxicity of AFB1 has been well documented, and we have previously reported the effect of the co-exposure on the liver (7). However, there is a dearth of information on the effect of co-exposure on oxidative damage in other organs. Therefore, in this study, we investigated if the co-exposure to AFB1 and low protein diet will increase oxidative stress in these organs. We hypothesize that co-exposure of weanling (3-week old) rats to AFB1 and low protein diet for eight weeks will increase oxidative stress in the extrahepatic tissues (erythrocytes, kidney, heart, brain, lungs, and spleen). We study oxidative stress by determining levels of lipid peroxidation, and enzymic and non-enzymic antioxidants in these tissues.

\section{MATERIALS AND METHODS}

Chemicals and reagents. Aflatoxin $\mathrm{B} 1$ was a product of Sigma-Aldrich (St. Louis, MO, USA) while reagent diagnostic kits for creatinine, urea, and uric acid were products of Cypress Diagnostics (Langdorp, Belgium). All other chemicals and reagents used in this study were of analytical grade.

Animals and animal feed. Twenty-four three-weekold male weanling rats were used for this study, and they were cared for in accordance with the Department of Biochemistry, Federal University of Agriculture, Abeokuta Animal Ethical Committee. The rats were housed in plastic cages at room temperature and kept under $12 \mathrm{hr}$ light and dark cycle. They had access to feed and water ad libitum throughout the experiment. The experimental diets were prepared according to AIN-93G and formulated to contain $40 \mathrm{ppb}$ AFB1 as previously described by Rotimi et al (7).

Experimental design. The animals were grouped as follows:

- NC: Rats fed normal protein diet $(20 \%)$

- PEM: Rats fed low protein diet (5\%)

- NA: Rats fed normal protein diet $(20 \%)$ and $40 \mathrm{ppb}$ AFB1

- PA: Rats fed low protein diet (5\%) and 40 ppb AFB1

The animals were maintained on this feed for eight weeks after which they were sacrificed by cardiac puncture under light anesthesia. Blood was collected into heparin tubes while the organs (kidney, heart, lungs, spleen, and brain) were excised and rinsed immediately in cold normal saline and kept at $-20^{\circ} \mathrm{C}$ until analysis. Packed Cell Volume (PCV) was determined using the hematocrit centrifuge while hemoglobin was determined according to the Drabkin's method as described by Sari et al (25).

Sample preparation. Plasma was obtained from whole blood by centrifugation at 3,000 rpm for $15 \mathrm{~min}$ at $4^{\circ} \mathrm{C}$ after which the erythrocytes were washed three times by suspension in normal saline, centrifugation at 3,000 rpm for $10 \mathrm{~min}$ at $4^{\circ} \mathrm{C}$ and aspiration of the supernatant.

$10 \%$ homogenate of a portion each organ was prepared in ice-cold homogenization buffer (125 mM sucrose, 125 $\mathrm{mM}$ mannitol, $1 \mathrm{mM}$ EGTA and $5 \mathrm{mM}$ HEPES) (pH 7.2 $0.25 \mathrm{M}$ ) using a Teflon pestle homogenizer. The homogenate was centrifuged at $3,000 \mathrm{rpm}$ for $15 \mathrm{~min}$ at $4^{\circ} \mathrm{C}$, and the supernatant was kept at $-20^{\circ} \mathrm{C}$ until analysis.

Biochemical analysis. The protein concentration of erythrocytes and tissue homogenates were determined spectrophotometrically according to the method of Lowry et al. (26) while plasma creatinine, urea, and uric acid levels were determined using Cypress kits according to the manufacturer's instructions.

Lipid Peroxidation was determined by measuring the concentration of thiobarbituric acid reactive substances (TBARS) according to the method of Buege and Aust 
(27). Glutathione concentration in the tissues was determined according to the method described by Ellman (28) while glutathione transferase activity was determined by measuring the formation of 1-chloro-2, 4-dinitrobenzene and GSH conjugate at $340 \mathrm{~nm}$ according to the method described by Habig et al (29). Glutathione peroxidase activity was determined according to the method of Rotruck et al (30). Superoxide dismutase activity was determined according to the pyrogallol autoxidation method of Marklund and Marklund (31) while peroxidase activity was determined according to the method of Ferusson and Chance (32). The activities of the enzymes in each organ were expressed per mg protein.

Statistical analysis. Data are expressed as mean \pm SEM. One-way analysis of variance (ANOVA), and Duncan's multiple range test were used to determine significant differences among the groups. A $p$-value $<0.05$ was considered significant.

\section{RESULTS}

The co-exposure of AFB1 and low protein significantly decreased the weight gain of the animals when compared with the normal control and PEM control (Table 1). The rats fed aflatoxin alone had significantly higher weight gain when compared with the PEM group and the PA group. Overall, weight gain decreased with each additional exposure $(\mathrm{NC}>\mathrm{NA}>\mathrm{PEM}>\mathrm{PA})$.

There was an increase in plasma creatinine concentration as a result of the co-exposure of AFB1 and low protein or either exposure alone (Table 2). There was no significant difference in uric acid and urea concentrations between NC and PEM groups. However, AFB1 alone significantly increased their concentrations while the coexposure of AFB1 and low protein led to further increase in the concentration of plasma uric acid and urea.

Hemoglobin concentration and packed cell volume (PCV) were significantly reduced by the co-exposure to

Table 1. Effect of co-exposure of AFB1 and low protein on the weight gain of the animals

\begin{tabular}{lcrr}
\hline \hline & Initial weight $(\mathrm{g})$ & Final weight $(\mathrm{g})$ & Weight gain $(\mathrm{g})$ \\
\hline $\mathrm{NC}$ & $29.17 \pm 1.74^{\mathrm{a}}$ & $164.67 \pm 3.99^{\mathrm{a}}$ & $135.50 \pm 5.06^{\mathrm{a}}$ \\
PEM & $30.33 \pm 1.45^{\mathrm{a}}$ & $84.33 \pm 6.31^{\mathrm{b}}$ & $54.00 \pm 7.16^{\mathrm{b}}$ \\
NA & $28.33 \pm 1.71^{\mathrm{a}}$ & $125.00 \pm 5.82^{\mathrm{c}}$ & $96.67 \pm 6.21^{\mathrm{c}}$ \\
PA & $28.83 \pm 1.58^{\mathrm{a}}$ & $64.17 \pm 3.03^{\mathrm{d}}$ & $35.33 \pm 3.58^{\mathrm{d}}$ \\
\hline
\end{tabular}

Values are mean \pm SEM $(n=6)$. Values within the same column with different alphabets are significantly different from each other at $p<0.05$. Initial weight was taken at 3 weeks and final weight was after 8 weeks of exposure.

NC: Rats fed normal protein diet (20\%), PEM: Rats fed low protein diet (5\%), NA: Rats fed normal protein diet (20\%) and 40 ppb AFB1, PA: Rats fed low protein diet (5\%) and 40 ppb AFB1.
Table 2. Effect of co-exposure of AFB1 and low protein on biomarkers of kidney functions

\begin{tabular}{llcc}
\hline \hline & \multicolumn{1}{c}{ Creatinine } & Uric acid & Urea \\
\hline NC & $0.64 \pm 0.01^{\mathrm{a}}$ & $3.82 \pm 0.02^{\mathrm{a}}$ & $12.36 \pm 0.07^{\mathrm{a}}$ \\
PEM & $1.29 \pm 0.11^{\mathrm{b}}$ & $3.96 \pm 0.18^{\mathrm{a}}$ & $12.94 \pm 0.19^{\mathrm{a}}$ \\
NA & $1.16 \pm 0^{\mathrm{b}}$ & $5.19 \pm 0.04^{\mathrm{b}}$ & $18.14 \pm 0.30^{\mathrm{b}}$ \\
PA & $1.29 \pm 0.02^{\mathrm{b}}$ & $7.23 \pm 0.06^{\mathrm{c}}$ & $19.24 \pm 0.32^{\mathrm{c}}$ \\
\hline
\end{tabular}

Values are mean \pm SEM $(n=6)$. Values within the same colum $n$ with different alphabets are significantly different from each other at $p<0.05$.

NC: Rats fed normal protein diet (20\%), PEM: Rats fed low protein diet $(5 \%), N A$ : Rats fed normal protein diet $(20 \%)$ and 40 ppb AFB1, PA: Rats fed low protein diet (5\%) and 40 ppb AFB1.

Table 3. Effect of co-exposure of AFB1 and low protein on hemoglobin and PCV

\begin{tabular}{lcc}
\hline \hline & Hemoglobin $(\mathrm{mg} / \mathrm{dL})$ & PCV $(\%)$ \\
\hline NC & $14.53 \pm 0.96^{\mathrm{a}}$ & $53.33 \pm 1.17^{\mathrm{a}}$ \\
PEM & $11.41 \pm 1.19^{\mathrm{b}}$ & $42.33 \pm 0.67^{\mathrm{c}}$ \\
NA & $4.97 \pm 0.51^{\mathrm{c}}$ & $48.83 \pm 0.95^{\mathrm{b}}$ \\
PA & $6.73 \pm 0.35^{\mathrm{c}}$ & $44.33 \pm 1.28^{\mathrm{c}}$ \\
\hline
\end{tabular}

Values are mean \pm SEM $(n=6)$. Values within the same colum $n$ with different alphabets are significantly different from each other at $p<0.05$.

NC: Rats fed normal protein diet (20\%), PEM: Rats fed low protein diet (5\%), NA: Rats fed normal protein diet $(20 \%)$ and 40 ppb AFB1, PA: Rats fed low protein diet (5\%) and 40 ppb AFB1.

AFB1 and low protein diet (Table 3). The PCV of PEM and PA groups were not significantly different from each other while the hemoglobin concentrations of NA and PA groups were not significantly different.

Co-exposure of AFB1 and low protein decreased glutathione peroxidase (GPx) in the erythrocytes, kidney, heart, brain, and spleen while an increase was observed in the lungs. In the erythrocytes, PEM alone decreased GPx activity when compared with the normal control group. The activity of GPx in the NA group was not significantly different from the PA group in all the tissues studied (Fig. 1).

The co-exposure significantly increased TBARS in all the tissues, compared with the normal control. The concentration of TBARS in the PEM group was significantly higher in all the tissues when compared with the NC group except for the erythrocytes and brain which was not significantly different from the NC group. The NA group had significantly higher TBARS levels in the erythrocytes and kidney when compared with the PA group. In the other tissues, the TBARS concentrations in PA and NA groups were not significantly different from each other. In the spleen, the concentration of TBARS in the PEM group was significantly higher than that of the other groups (Fig. 2).

The activity of glutathione-S-transferase (GST) was significantly decreased in all the tissues as a result of the coexposure. GST in the NA and PA groups was not signifi- 

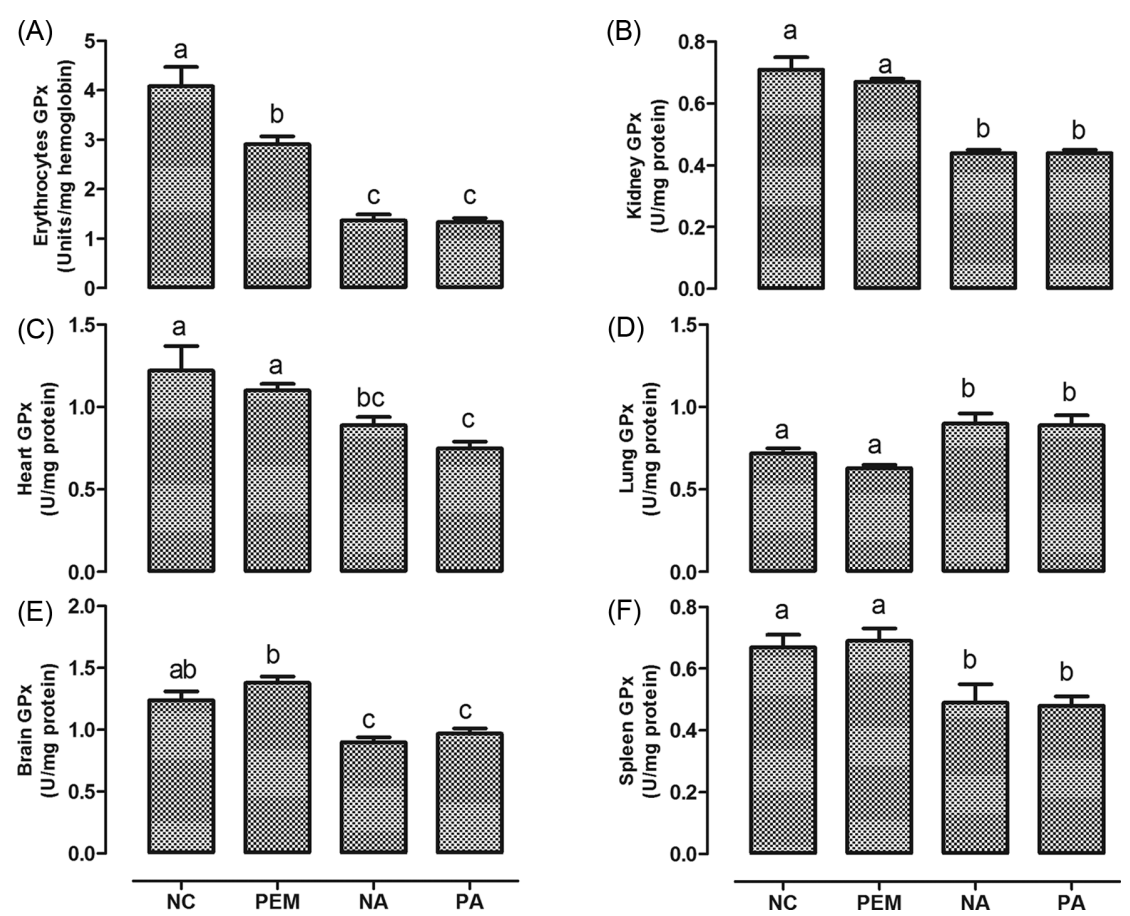

Fig. 1. Effect of co-exposure of AFB1 and low protein on glutathione peroxidase activity in (A) erythrocyte, (B) kidney, (C) heart, (D) lung, $(E)$ brain and $(F)$ spleen of the rats. Bars represent mean \pm SEM $(n=6)$. Bars with different alphabets are significantly different from each other at $p<0.05$. NC: Rats fed normal protein diet (20\%), PEM: Rats fed low protein diet (5\%), NA: Rats fed normal protein diet (20\%) and 40 ppb AFB1, PA: Rats fed low protein diet (5\%) and 40 ppb AFB1.
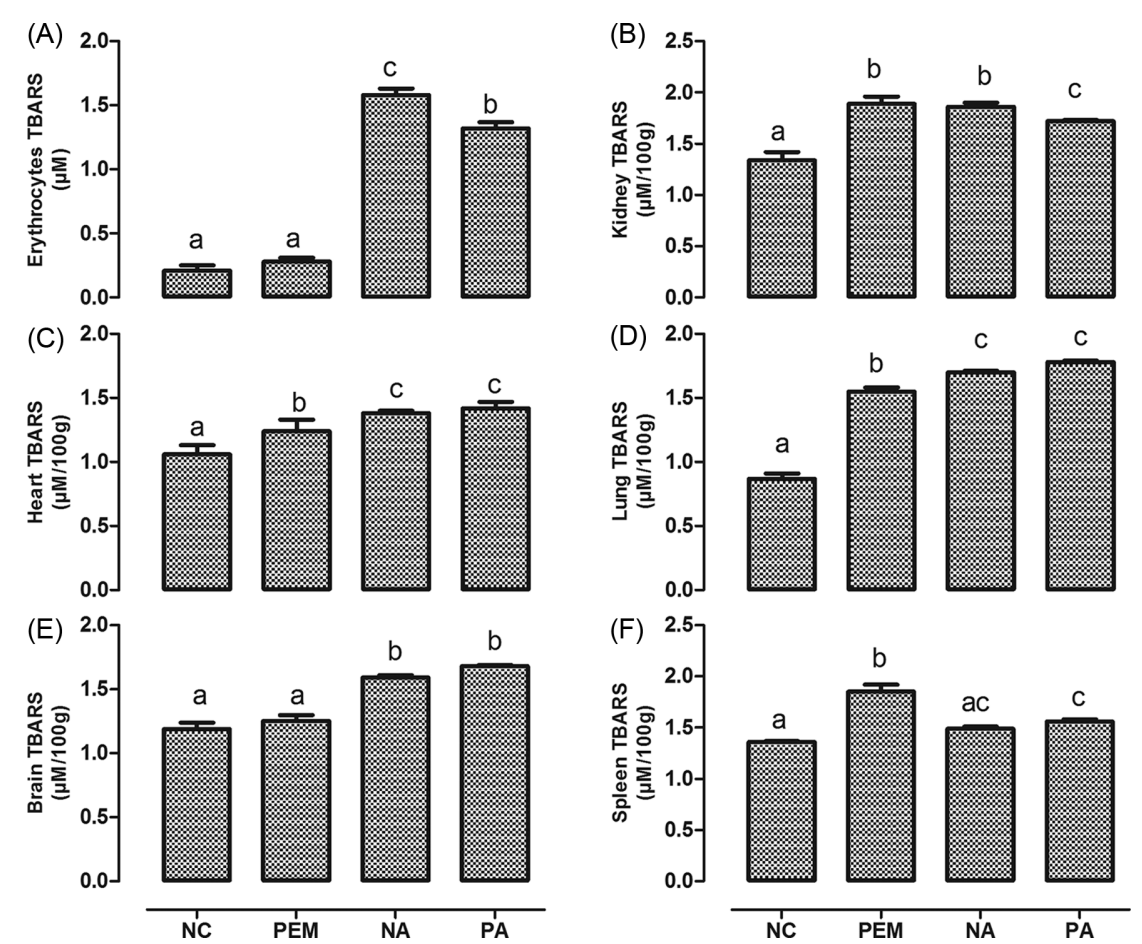

Fig. 2. Effect of co-exposure of AFB1 and low protein on TBARS in (A) erythrocyte, (B) kidney, (C) heart, (D) lung, (E) brain and (F) spleen of the rats. Bars represent mean $\pm \operatorname{SEM}(n=6)$. Bars with different alphabets are significantly different from each other at $p<0.05$. NC: Rats fed normal protein diet (20\%), PEM: Rats fed low protein diet (5\%), NA: Rats fed normal protein diet (20\%) and $40 \mathrm{ppb}$ AFB1, PA: Rats fed low protein diet (5\%) and 40 ppb AFB1. 

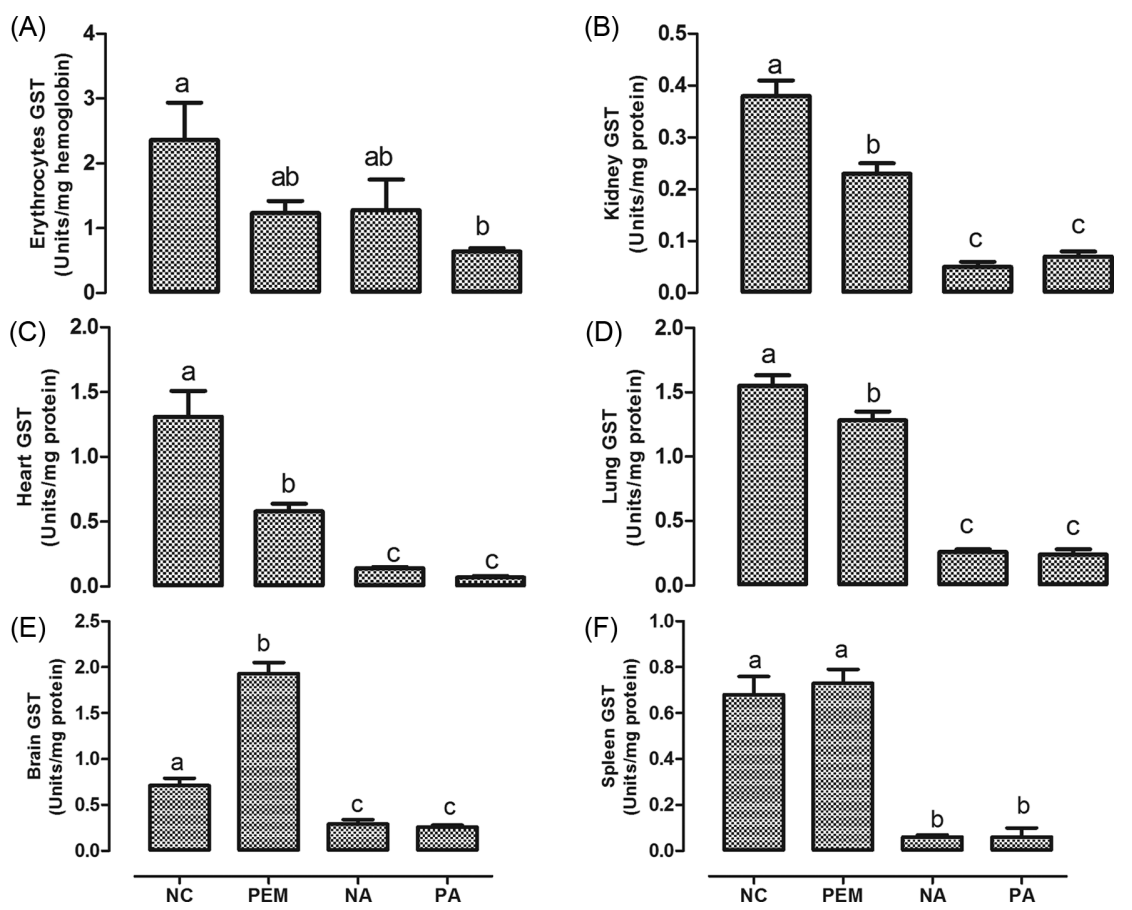

Fig. 3. Effect of co-exposure of AFB1 and low protein on glutathione -S- transferase activity in (A) erythrocyte, (B) kidney, (C) heart, (D) lung, $(E)$ brain and $(F)$ spleen of the rats. Bars represent mean $\pm \operatorname{SEM}(n=6)$. Bars with different alphabets are significantly different from each other at $p<0.05$. NC: Rats fed normal protein diet (20\%), PEM: Rats fed low protein diet (5\%), NA: Rats fed normal protein diet (20\%) and 40 ppb AFB1, PA: Rats fed low protein diet (5\%) and 40 ppb AFB1.
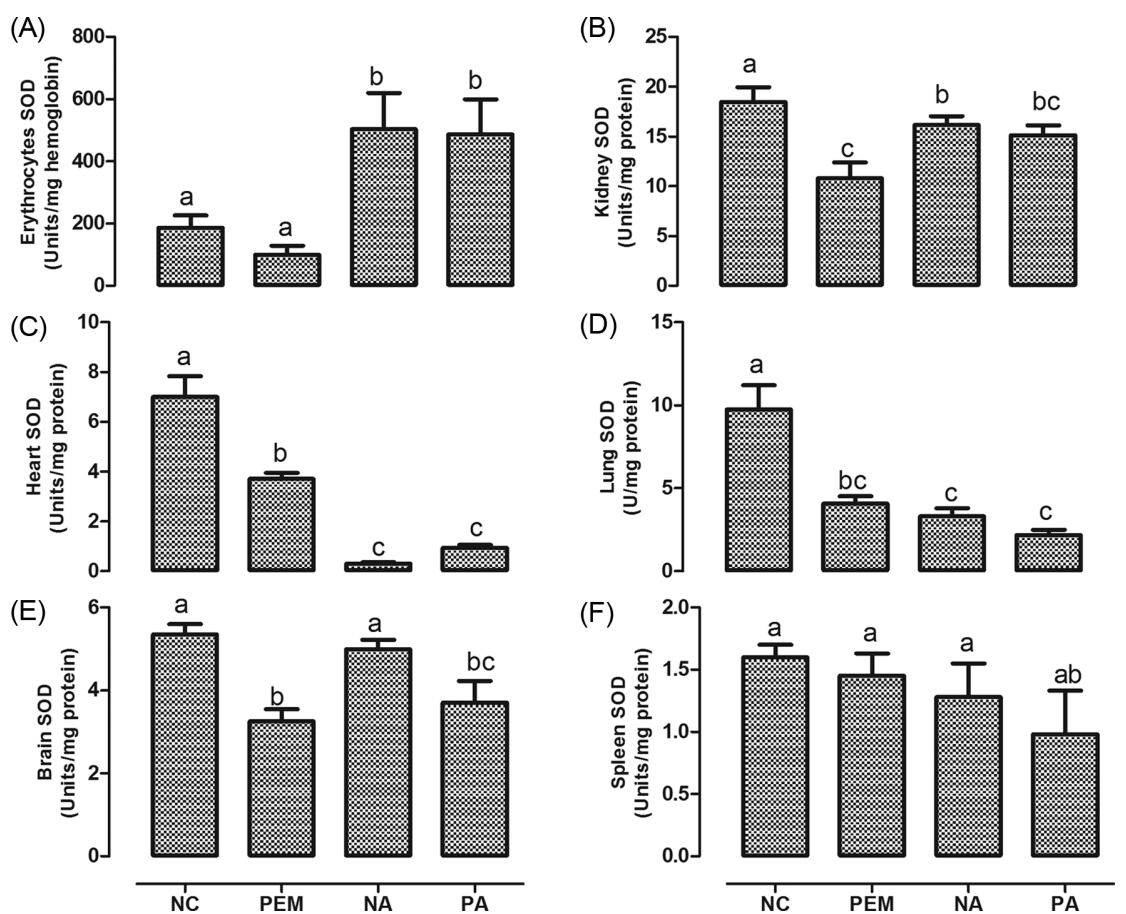

Fig. 4. Effect of co-exposure of AFB1 and low protein on superoxide dismutase activity in (A) erythrocyte, (B) kidney, (C) heart, (D) lung, $(E)$ brain and $(F)$ spleen of the rats. Bars represent mean \pm SEM $(n=6)$. Bars with different alphabets are significantly different from each other at $p<0.05$. NC: Rats fed normal protein diet (20\%), PEM: Rats fed low protein diet (5\%), NA: Rats fed normal protein diet (20\%) and 40 ppb AFB1, PA: Rats fed low protein diet (5\%) and 40 ppb AFB1. 

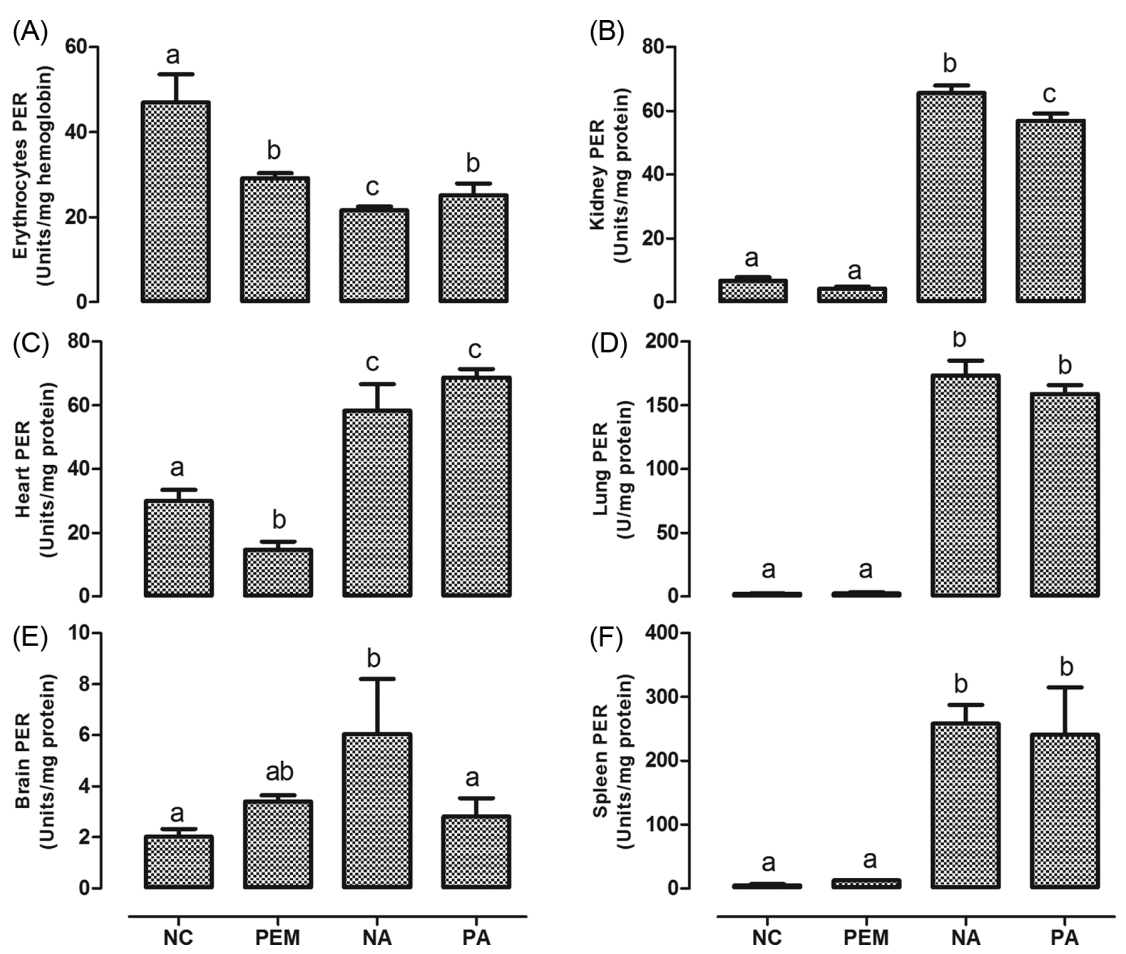

Fig. 5. Effect of co-exposure of $A F B 1$ and low protein on peroxidase activity in (A) erythrocyte, (B) kidney, (C) heart, (D) lung, (E) brain and $(F)$ spleen of the rats. Bars represent mean \pm SEM $(n=6)$. Bars with different alphabets are significantly different from each other at $p<0.05$. NC: Rats fed normal protein diet (20\%), PEM: Rats fed low protein diet (5\%), NA: Rats fed normal protein diet (20\%) and 40 ppb AFB1, PA: Rats fed low protein diet (5\%) and 40 ppb AFB1.
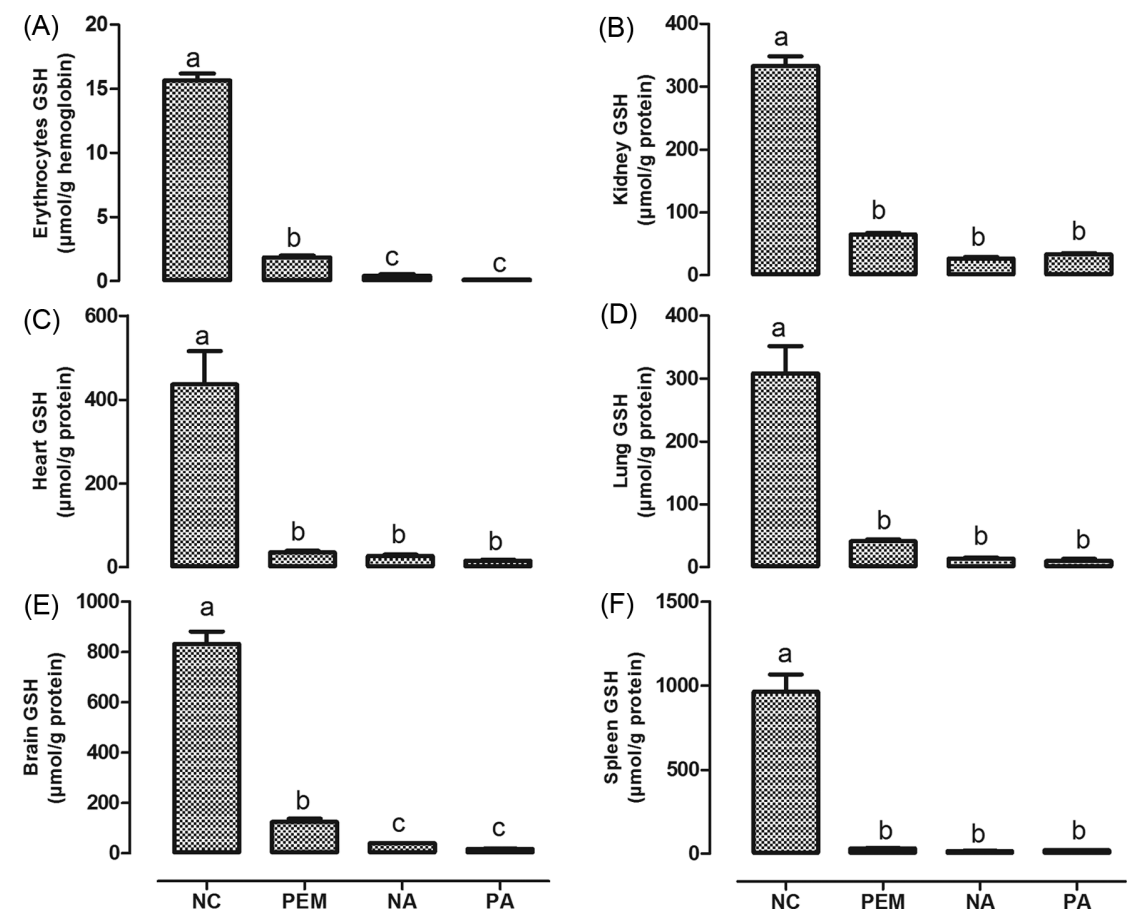

Fig. 6. Effect of co-exposure of AFB1 and low protein on glutathione concentrations in (A) erythrocyte, (B) kidney, (C) heart, (D) lung, (E) brain and (F) spleen of the rats. Bars represent mean \pm SEM $(n=6)$. Bars with different alphabets are significantly different from each other at $p<0.05$. NC: Rats fed normal protein diet (20\%), PEM: Rats fed low protein diet (5\%), NA: Rats fed normal protein diet (20\%) and 40 ppb AFB1, PA: Rats fed low protein diet (5\%) and 40 ppb AFB1. 
cantly different from each other in any tissue except erythrocytes. GST activity in the PEM group was significantly lower than that of the NC group in all the tissues except the brain - which had increased activity - and the spleen which was not significantly different (Fig. 3).

The activity of superoxide dismutase (SOD) significantly increased in the erythrocyte while its activity in the other organs was decreased due to the co-exposure. PEM alone also significantly decreased the activity of SOD in all the tissues - except the spleen compared with the NC group (Fig. 4).

Co-exposure of AFB1 and low protein significantly increased peroxidase (PER) activities in the kidney, lungs, heart, and spleen while it significantly decreased peroxidase activity in the erythrocyte. No significant difference was observed in the brain when compared to the NC group (Fig. 5).

Glutathione (GSH) was significantly decreased and nearly depleted in the erythrocyte and all the organs following exposure to AFB1 and low protein in combination or separately (Fig. 6). When compared with the PEM group, the PA group had significantly lower GSH in the erythrocytes and brain (Fig. 6).

\section{DISCUSSION}

This study demonstrates that early-life co-exposure to AFB1 and low protein diet for 8 weeks decreased body weight gain, affected kidney function, and induced oxidative stress in extrahepatic tissues of weanling rats. TBARS was used as an expression of lipid peroxidation while GSH concentrations as well as enzyme activity of GPx, GST, SOD, and PER which help to defend the tissues against oxidative insults (33) were used as indicators of oxidant/antioxidant status. These results complement our previous study showing oxidative stress, apoptosis, and genomic alterations in the liver following the same exposure paradigm (7). The exposure model used here is particularly relevant as infants and young children in many developing countries are exposed to AFB1 and a primarily low-protein diet following weaning.

A crucial morphological evidence of malnutrition is impaired physical development (17,34). In this study, while low protein diet alone significantly reduced the weight gain of the animals, co-exposure with AFB1 led to a further reduction in weight gain. Several studies have reported that AFB1 caused growth impairment in children (9-12) and other studies have shown that a low protein diet could affect proper growth in children (17). In this study, AFB1 and low protein diet had an additive effect on reducing weight gain over 8 weeks. The decrease in weight gain observed in rats fed low protein diet could be as a result of low feed intake (data not shown). This could be a result of reduced palatability due to low protein. Previous studies have shown that rats fed low protein diet consumed less feed and gained less weight $(35,36)$. AFB1 has also been shown to reduce food intake and ultimately body weight gain by decreasing the expression of hypothalamic neuropeptides, orexigenic and anorexigenic, that regulate feed intake (24). This effect has been shown to be dose-specific (24) and may explain the reason why the feed intake of rats fed AFB1 was not significantly different from normal rats since we used a low dose in this study. Apart from reducing feed intake, other mechanisms by which AFB1 could impair growth in children have been proposed, these include: 1) changes in gastrointestinal tract thereby preventing the proper absorption and utilization of nutrients, 2) immunosuppressive effects of AFB1 could increase susceptibility to other infections which can cause growth impairment, 3) AFB1-induced changes in carbohydrate and lipid metabolism, and 4) downregulation of insulin-like growth factor genes by AFB1 $(9,37,38)$.

Plasma creatinine, uric acid, and urea which are considered biomarkers of kidney function were increased in this study, indicating renal dysfunction. Although rats fed low protein diet alone did not have any change in uric acid and urea, AFB1 significantly increased the concentration of the biomarkers and co-exposure led to further increases in the biomarkers of kidney function, suggesting potentiation. This is consistent with other studies that reported that AFB1 increased the levels of these biomarkers $(39,40)$. The renal injury observed could be linked to increased oxidative stress observed in the kidney. In this study, coexposure of AFB1 and low protein increased TBARS and PER while GSH, GPx, SOD, and GST were decreased in the kidney indicating a pro-oxidant environment. This observation is also consistent with the response of the heart to AFB1 exposure, and the cardio- and reno-toxicity of AFB1 has been previously reported $(19,20)$.

In this study, we observed different tissues responses to oxidative stress resulting from co-exposure to AFB1 and low protein diet. The different responses could be due to differences in the structure and function of these tissues. Precisely, we found that co-exposure to AFB1 and low protein diet significantly increased lipid peroxidation while GSH was depleted across all the tissues. The increase in lipid peroxidation could be due to the ability of AFB1 to increase oxidant levels in tissues after it is metabolized to a highly reactive epoxide that binds to biomolecules (5). GSH directly scavenges free radicals and/or take part in enzymatic detoxification together with GST, which catalyzes the detoxification of xenobiotics, and GPx - which reduces hydroperoxides- hence protecting the tissues from oxidative stress. The depletion in GSH in all the tissues studied could be a result of the increased oxidant status caused by AFB1 and the low protein diet. GSH is a tripeptide; therefore an optimal protein in the diet is necessary for its synthesis and studies have also shown that GSH is 
depleted during protein malnutrition (18). The ability of these tissues to maintain high levels of antioxidant enzymes in response to pro-oxidants is important for preventing oxidative stress; hence, the decrease in the activities of these enzymes could have led to oxidative stress in these tissues.

In the erythrocytes, the co-exposure significantly increased lipid peroxidation and SOD while GSH, GPx, GST, and PER were significantly decreased. Increased lipid peroxidation in the erythrocytes leads to erythrocytic burst with a concomitant increase in hemolysis; hence, this could account for the low PCV and hemoglobin level observed in this study. Previous studies have shown that AFB1 decreased the PCV and hemoglobin of rabbits (41) and broiler chicks (42). Huang et al. (35) found that rats fed low protein had lower hematocrit and hemoglobin than those fed normal protein. Unlike other tissues, erythrocytes lack the nucleus and depend only on mRNA remnant from premature erythrocytes to sustain themselves. Hence, AFB1 could decrease the lifespan of the erythrocytes by inducing oxidative stress which could account for the increased hemolysis and low PCV. After the erythrocytes have lived their lifespan, they are removed from the blood by macrophages in the red pulp compartment of the spleen. Apart from its role in removing old erythrocytes, the spleen is also involved in immune function (43) and has been found to play a role in innate and adaptive immune response. We observed increase in oxidative stress in the spleen of the rats, and this could impair the normal function of the spleen. AFB1 has been shown to increase oxidative stress and apoptosis (23), cause ultrastructural changes in the spleen of broilers (44) and modulate the spleen transcriptome in turkey (45). Co-exposure could compromise this effect since there is evidence that protein deprivation could decrease splenic B and T- cells thereby increasing susceptibility to infections (46). Although previous studies have reported compromised immune status in children with malnutrition and those exposed to AFB1 $(8,17)$, we demonstrate in this study that oxidative stress-induced impairment to the spleen could be part of the mechanism involved in this compromised immune function.

Co-exposure to AFB1 and low protein diet significantly increased lipid peroxidation while GSH, GPx, GST, and SOD were significantly decreased in the brain. The brain is a lipid-rich tissue; therefore, prone to lipid peroxidation and AFB1 has been shown to have the ability to cross the blood-brain barrier (47). The findings of this study are in agreement with other studies and could explain the neurotoxic effects of AFB1 $(21,24,47,48)$. In addition, low protein diet has been shown to increase oxidative stress in different parts of the brain thereby resulting in cognitive dysfunction $(49,50)$.

Previous studies have demonstrated that both protein malnutrition and AFB1 exposure independently result in multiple organ dysfunctions. The results of this study corroborate previous works and show the effect of AFB1 and/ or protein malnutrition alone on oxidative stress in multiple tissues in young rats exposed at a vulnerable time period in development - following weaning. Results also suggest additive effects of AFB1 and protein malnutrition on decreased weight gain and potentiation of kidney dysfunction with co-exposure. Oxidative damage was induced by the co-exposure in all organs studied, and coupled with previous findings in the liver (7), results demonstrate that co-exposure to AFB1 and low protein diet should be a public health concern especially for children in developing countries where AFB1 contamination is common.

Received February 12, 2018; Revised March 27, 2018; Accepted April 5, 2018

\section{REFERENCES}

1. Pitt, J., Taniwaki, M.H. and Cole, M. (2013) Mycotoxin production in major crops as influenced by growing, harvesting, storage and processing, with emphasis on the achievement of Food Safety Objectives. Food Control, 32, 205-215.

2. Mitchell, N.J., Hsu, H.-H., Chandyo, R.K., Shrestha, B., Bodhidatta, L., Tu, Y.-K., Gong, Y.-Y., Egner, P.A., Ulak, M. and Groopman, J.D. (2017) Aflatoxin exposure during the first 36 months of life was not associated with impaired growth in Nepalese children: an extension of the MAL-ED study. PLoS ONE, 12, e 0172124.

3. Cho, S.Y., Kang, S.J., Jung, J., Jeong, B.O. and Jeong, C.S. (2009) Co-contamination of aflatoxins with ochratoxin A and zearalenone in Thuja orientalis Semen. Toxicol. Res., 25, 125-131.

4. Watson, S., Gong, Y.Y. and Routledge, M. (2017) Interventions targeting child undernutrition in developing countries may be undermined by dietary exposure to aflatoxin. Crit. Rev. Food Sci. Nutr., 57, 1963-1975.

5. Dohnal, V., Wu, Q. and Kuča, K. (2014) Metabolism of aflatoxins: key enzymes and interindividual as well as interspecies differences. Arch. Toxicol., 88, 1635-1644.

6. Marin, D.E. and Taranu, I. (2012) Overview on aflatoxins and oxidative stress. Toxin Rev., 31, 32-43.

7. Rotimi, O.A., Rotimi, S.O., Oluwafemi, F., Ademuyiwa, O. and Balogun, E.A. (2016) Coexistence of aflatoxicosis with protein malnutrition worsens hepatic oxidative damage in rats. J. Biochem. Mol. Toxicol., 30, 269-276.

8. Turner, P.C., Moore, S.E., Hall, A.J., Prentice, A.M. and Wild, C.P. (2003) Modification of immune function through exposure to dietary aflatoxin in Gambian children. Environ. Health Perspect., 111, 217.

9. Khlangwiset, P., Shephard, G.S. and Wu, F. (2011) Aflatoxins and growth impairment: a review. Crit. Rev. Toxicol., 41, 740-755.

10. Turner, P.C., Collinson, A.C., Cheung, Y.B., Gong, Y., Hall, A.J., Prentice, A.M. and Wild, C.P. (2007) Aflatoxin exposure in utero causes growth faltering in Gambian infants. Int. J. Epidemiol., 36, 1119-1125. 
11. Gong, Y., Egal, S., Hounsa, A., Turner, P., Hall, A., Cardwell, K. and Wild, C. (2003) Determinants of aflatoxin exposure in young children from Benin and Togo, West Africa: the critical role of weaning. Int. J. Epidemiol., 32, 556-562.

12. Gong, Y., Hounsa, A., Egal, S., Turner, P.C., Sutcliffe, A.E., Hall, A.J., Cardwell, K. and Wild, C.P. (2004) Postweaning exposure to aflatoxin results in impaired child growth: a longitudinal study in Benin, West Africa. Environ. Health Perspect., 112, 1334.

13. Chen, G., Gong, Y.Y., Kimanya, M.E., Shirima, C.P. and Routledge, M.N. (2017) Comparison of urinary aflatoxin M1 and aflatoxin albumin adducts as biomarkers for assessing aflatoxin exposure in Tanzanian children. Biomarkers, 23, 131-136.

14. Routledge, M.N., Kimanya, M.E., Shirima, C.P., Wild, C.P. and Gong, Y.Y. (2014) Quantitative correlation of aflatoxin biomarker with dietary intake of aflatoxin in Tanzanian children. Biomarkers, 19, 430-435.

15. Adetunji, M.C., Atanda, O.O. and Ezekiel, C.N. (2017) Risk assessment of mycotoxins in stored maize grains consumed by infants and young children in Nigeria. Children, 4, 58.

16. Müller, O. and Krawinkel, M. (2005) Malnutrition and health in developing countries. Can. Med. Assoc. J., 173, 279-286.

17. Grover, Z. and Ee, L.C. (2009) Protein energy malnutrition. Pediatr. Clin. North Am., 56, 1055-1068.

18. Khare, M., Mohanty, C., Das, B., Jyoti, A., Mukhopadhyay, B. and Mishra, S. (2014) Free radicals and antioxidant status in protein energy malnutrition. Int. J. Pediatr., 2014, 254396.

19. Ge, J., Yu, H., Li, J., Lian, Z., Zhang, H., Fang, H. and Qian, L. (2017) Assessment of aflatoxin B1 myocardial toxicity in rats: mitochondrial damage and cellular apoptosis in cardiomyocytes induced by aflatoxin B1. J. Int. Med. Res., 45, 1015-1023.

20. Abdulmajeed, N.A. (2011) Therapeutic ability of some plant extracts on aflatoxin B1 induced renal and cardiac damage. Arab. J. Chem., 4, 1-10.

21. Linardaki, Z.I., Lamari, F.N. and Margarity, M. (2017) Saffron (Crocus sativus L.) tea intake prevents learning/memory defects and neurobiochemical alterations induced by aflatoxin B1 exposure in adult mice. Neurochem. Res., 42, 2743-2754.

22. Yang, X.-J., Lu, H.-Y., Li, Z.-Y., Bian, Q., Qiu, L.-L., Li, Z., Liu, Q., Li, J., Wang, X. and Wang, S.-L. (2012) Cytochrome P450 2A13 mediates aflatoxin B1-induced cytotoxicity and apoptosis in human bronchial epithelial cells. Toxicology, 300, 138-148.

23. Chen, J., Chen, K., Yuan, S., Peng, X., Fang, J., Wang, F., Cui, H., Chen, Z., Yuan, J. and Geng, Y. (2016) Effects of aflatoxin B1 on oxidative stress markers and apoptosis of spleens in broilers. Toxicol. Ind. Health, 32, 278-284.

24. Trebak, F., Alaoui, A., Alexandre, D., El Ouezzani, S., Anouar, Y., Chartrel, N. and Magoul, R. (2015) Impact of aflatoxin $\mathrm{B} 1$ on hypothalamic neuropeptides regulating feeding behavior. Neurotoxicology, 49, 165-173.

25. Sari, M., Pee, S.D., Martini, E., Herman, S., Bloem, M.W. and Yip, R. (2001) Estimating the prevalence of anaemia: a comparison of three methods. Bull. World Health Organ., 79, 506-511.

26. Lowry, O.H., Rosebrough, N.J., Farr, A.L. and Randall, R.J. (1951) Protein measurement with the Folin phenol reagent. J. Biol. Chem., 193, 265-275.

27. Buege, J.A. and Aust, S.D. (1978) Microsomal lipid peroxidation. Methods Enzymol., 52, 302-310.

28. Ellman, G.L. (1959) Tissue sulfhydryl groups. Arch. Biochem. Biophys., 82, 70-77.

29. Habig, W.H., Pabst, M.J. and Jakoby, W.B. (1974) Glutathione S-transferases the first enzymatic step in mercapturic acid formation. J. Biol. Chem., 249, 7130-7139.

30. Rotruck, J.T., Pope, A.L., Ganther, H., Swanson, A., Hafeman, D.G. and Hoekstra, W. (1973) Selenium: biochemical role as a component of glutathione peroxidase. Science, 179, 588-590.

31. Marklund, S. and Marklund, G. (1974) Involvement of the superoxide anion radical in the autoxidation of pyrogallol and a convenient assay for superoxide dismutase. FEBS J., 47, 469-474.

32. Fergusson, R. and Chance, B. (1955) Substrate specificity of peroxidase. Science, 122, 466-467.

33. Kanbur, M., Eraslan, G., Sarıca, Z.S. and Aslan, Ö. (2011) The effects of evening primrose oil on lipid peroxidation induced by subacute aflatoxin exposure in mice. Food Chem. Toxicol., 49, 1960-1964.

34. De Onis, M., Onyango, A.W., Borghi, E., Garza, C. and Yang, H. (2006) Comparison of the World Health Organization (WHO) Child Growth Standards and the National Center for Health Statistics/WHO international growth reference: implications for child health programmes. Public Health Nutr., 9, 942-947.

35. Huang, C.-J. and Fwu, M.-L. (1993) Degree of protein deficiency affects the extent of the depression of the antioxidative enzyme activities and the enhancement of tissue lipid peroxidation in rats. J. Nutr., 123, 803-810.

36. Alaverdashvili, M., Hackett, M.J., Caine, S. and Paterson, P.G. (2017) Parallel changes in cortical neuron biochemistry and motor function in protein-energy malnourished adult rats. NeuroImage, 149, 275-284.

37. Castelino, J.M., Routledge, M.N., Wilson, S., Dunne, D.W., Mwatha, J.K., Gachuhi, K., Wild, C.P. and Gong, Y.Y. (2015) Aflatoxin exposure is inversely associated with IGF1 and IGFBP3 levels in vitro and in Kenyan schoolchildren. Mol. Nutr. Food Res., 59, 574-581.

38. Smith, L.E., Stoltzfus, R.J. and Prendergast, A. (2012) Food chain mycotoxin exposure, gut health, and impaired growth: a conceptual framework. Adv. Nutr., 3, 526-531.

39. El-Nekeety, A.A., Mohamed, S.R., Hathout, A.S., Hassan, N.S., Aly, S.E. and Abdel-Wahhab, M.A. (2011) Antioxidant properties of Thymus vulgaris oil against aflatoxininduce oxidative stress in male rats. Toxicon, 57, 984-991.

40. Eraslan, G., Sarıca, Z.S., Bayram, L.Ç., Tekeli, M.Y., Kanbur, M. and Karabacak, M. (2017) The effects of diosmin on aflatoxin-induced liver and kidney damage. Environ. Sci. Pollut. Res. Int., 24, 27931-27941.

41. Attia, Y., Allakany, H., Abd Al Hamid, A., Al Saffar, A., Hassan, R. and Mohamed, N. (2013) Capability of different non nutritive feed additives on improving productive and 
physiological traits of broiler chicks fed diets with or without aflatoxin during the first 3 weeks of life. J. Anim. Physiol. Anim. Nutr. (Berl.), 97, 754-772.

42. Yousef, M., Salem, M., Kamel, K., Hassan, G. and El Nouty, F. (2003) Influence of ascorbic acid supplementation on the haematological and clinical biochemistry parameters of male rabbits exposed to aflatoxin B1. J. Environ. Sci. Health B, 38, 193-209.

43. Mebius, R.E. and Kraal, G. (2005) Structure and function of the spleen. Nat. Rev. Immunol., 5, 606-616.

44. Peng, X., Bai, S., Ding, X., Zeng, Q., Zhang, K. and Fang, J. (2015) Pathological changes in the immune organs of broiler chickens fed on corn naturally contaminated with aflatoxins B1 and B2. Avian Pathol., 44, 192-199.

45. Monson, M.S., Settlage, R.E., Mendoza, K.M., Rawal, S., El-Nezami, H.S., Coulombe, R.A. and Reed, K.M. (2015) Modulation of the spleen transcriptome in domestic turkey (Meleagris gallopavo) in response to aflatoxin B1 and probiotics. Immunogenetics, 67, 163-178.

46. Mello, A.S., de Oliveira, D.C., Bizzarro, B., Sá-Nunes, A., Hastreiter, A.A., de Oliveira Beltran, J.S., Xavier, J.G., Borelli, P. and Fock, R.A. (2014) Protein malnutrition alters spleen cell proliferation and IL-2 and IL-10 production by affecting the STAT-1 and STAT-3 balance. Inflammation, 37, 2125-2138.

47. Qureshi, H., Hamid, S.S., Ali, S.S., Anwar, J., Siddiqui, A.A. and Khan, N.A. (2015) Cytotoxic effects of aflatoxin B1 on human brain microvascular endothelial cells of the blood-brain barrier. Med. Mycol., 53, 409-416.

48. Souto, N.S., Claudia Monteiro Braga, A., Lutchemeyer de Freitas, M., Rechia Fighera, M., Royes, L.F.F., Schneider Oliveira, M. and Furian, A.F. (2017) Aflatoxin B1 reduces non-enzymatic antioxidant defenses and increases protein kinase $\mathrm{C}$ activation in the cerebral cortex of young rats. Nutr. Neurosci., 21, 268-275.

49. Feoli, A.M., Siqueira, I.R., Almeida, L., Tramontina, A.C., Vanzella, C., Sbaraini, S., Schweigert, I.D., Netto, C.A., Perry, M.L. and Gonçalves, C.A. (2006) Effects of protein malnutrition on oxidative status in rat brain. Nutrition, 22, 160-165.

50. Adebayo, O.L., Adenuga, G.A. and Sandhir, R. (2016) Selenium and zinc protect brain mitochondrial antioxidants and electron transport chain enzymes following postnatal protein malnutrition. Life Sci., 152, 145-155. 